\section{OPEN ACCESS}

Edited by:

Sara Pedron,

University of Illinois at

Urbana-Champaign, United States

Reviewed by:

Pilnam Kim,

Korea Advanced Institute of Science \&

Technology (KAIST), South Korea

Alexander Birbrair,

Universidade Federal de Minas Gerais,

Brazil

*Correspondence:

Jennifer M. Munson

munsonj@vt.edu

Specialty section:

This article was submitted to Biomaterials,

a section of the journal

Frontiers in Materials

Received: 01 February 2018 Accepted: 19 April 2018 Published: 09 May 2018

Citation:

Cornelison RC and Munson JM (2018)

Perspective on Translating

Biomaterials Into Glioma Therapy:

Lessons From in Vitro Models.

Front. Mater. 5:27.

doi: 10.3389/fmats.2018.00027

\title{
Perspective on Translating Biomaterials Into Glioma Therapy: Lessons From in Vitro Models
}

\section{R. Chase Cornelison and Jennifer M. Munson*}

Department of Biomedical Engineering and Mechanics, Virginia Polytechnic Institute and State University, Blacksburg, VA, United States

Glioblastoma (GBM) is the most common and malignant form of brain cancer. Even with aggressive standard of care, GBM almost always recurs because its diffuse, infiltrative nature makes these tumors difficult to treat. The use of biomaterials is one strategy that has been, and is being, employed to study and overcome recurrence. Biomaterials have been used in GBM in two ways: in vitro as mediums in which to model the tumor microenvironment, and in vivo to sustain release of cytotoxic therapeutics. In vitro systems are a useful platform for studying the effects of drugs and tissue-level effectors on tumor cells in a physiologically relevant context. These systems have aided examination of how glioma cells respond to a variety of natural, synthetic, and semi-synthetic biomaterials with varying substrate properties, biochemical factor presentations, and non-malignant parenchymal cell compositions in both 2D and 3D environments. The current in vivo paradigm is completely different, however. Polymeric implants are simply used to line the post-surgical resection cavities and deliver secondary therapies, offering moderate impacts on survival. Instead, perhaps we can use the data generated from in vitro systems to design novel biomaterial-based treatments for GBM akin to a tissue engineering approach. Here we offer our perspective on the topic, summarizing how biomaterials have been used to identify facets of glioma biology in vitro and discussing the elements that show promise for translating these systems in vivo as new therapies for GBM.

Keywords: glioblastoma, biomaterial, hydrogel, regenerative medicine, tissue engineering, brain, tumor microenvironment

\section{INTRODUCTION}

Glioblastoma (GBM) is a high-grade brain cancer that almost always recurs (Cuddapah et al., 2014). Many in vitro and in vivo models of GBM have been developed in an effort to uncover new therapeutic strategies. Biomaterials are often primary components of in vitro models to chemically, mechanically, and/or topographically recreate the physiological tumor environment, as recently reviewed by Xiao et al. (2017), Gu and Mooney (2015), Pradhan et al. (2016), Cha and Kim (2017), and Heffernan and Sirianni (2018).

While GBM models are useful for studying glioma biology, the field is far from accurately predicting clinical success of a new therapy. It was recently suggested that all models, including gold-standard mouse xenografts, inherently cannot preserve the genetic landscape of patient-derived tumor cells (Ben-David et al., 2017). Where does this study (and others 
like it) leave the field? Glioma is a tissue, with complex heterogeneity in tissue geometry, composition, biophysical properties, etc. Even if researchers can create sophisticated models of the tumor, these models cannot logistically account for every element of the in vivo environment. Therefore, a tissuelevel approach may enhance our ability to treat this deadly disease.

In vitro biomaterial research has revealed crucial information about material-GBM cell interactions. And yet, implementation of biomaterials in vivo for treating GBM has been limited to anti-tumor drug delivery, such as BCNU-releasing Gliadel wafers (Wait et al., 2015). These wafers, made of a poly(lactic-coglycolic) polymer backbone, have been used to line resection cavities in patients receiving surgical removal of primary tumors and offer a modest, yet significant, increase in survival. However, these systems are simply a conduit for therapy and thus in no way leverage glioma-biomaterial interactions as part of the therapy.

Many diseases are now being viewed from a regenerative medicine lens, using factors within the patient's own body to promote healing. Cancer is often described as a wound that does not heal and may similarly benefit from this approach. The fluid-filled cavity remaining after resection is a prime space in which to examine biomaterial-based therapies, analogous to experimental treatments for stroke or traumatic brain injury. In current literature, treating the post-resection cavity has primarily involved hydrogel biomaterials as passive vehicles for drug therapy (Bagó et al., 2016; Bastiancich et al., 2017). It is possible that translating collective knowledge from myriad in vitro models could instead transition biomaterials to an active avenue for cancer remediation. Below, we summarize current understanding of how glioma outcomes can be altered in vitro and offer perspectives for using this data to design biomaterials for promoting anti-tumor responses, tumor targeting, and treatment against glioblastoma.

\section{TUNING THE EXTRACELLULAR MATRIX}

\section{Matrix Composition}

While earlier experiments with glioma cells used 2D plastic, it is now understood that the underlying matrix plays an important role in glioma phenotype (Eke and Cordes, 2011; Florczyk et al., 2013; Heffernan et al., 2015). The composition of the brain matrix is different from most tissues, primarily comprising the polysaccharide hyaluronic acid (HA) and HA-binding proteoglycans, but few fibrillar proteins. Many engineered in vitro systems for GBM therefore employ HA-based matrices. These models have elucidated that HA increases stem cell maintenance, glioma cell adhesion and migration, and markers of malignancy (Pedron et al., 2013; Kim and Kumar, 2014; Tilghman et al., 2014; Cha et al., 2016). Other brain components, such as certain chondroitin sulfate proteoglycans (CSPGs), have also been shown to increase glioma invasion (Logun et al., 2016). However, CSPGs have also been suggested to inhibit glioma cell invasion (Silver et al., 2013), therefore the specific response may depend on CSPG sulfation pattern (Silver and Silver, 2014).

Several in vitro models have been developed with components not ubiquitous in the brain, like collagen I and laminin-rich basement membrane extract (Matrigel). While mixing these components with HA can recreate the invasive phenotypes observed in pure HA hydrogels (Munson et al., 2013; Gritsenko et al., 2017), collagen and Matrigel hydrogels alone comparatively limit glioma cell invasion. Some non-native components nonetheless increase invasion: The extracellular matrix (ECM) secreted by glioma cells is itself dissimilar to the native brain and is rich in aberrant proteoglycans, tenascin-c, and an overabundance of HA (Cuddapah et al., 2014; Xia et al., 2016). For example, glioma cells secrete a truncated form of the proteoglycan brevican which binds to fibronectin and promotes invasion ( $\mathrm{Hu}$ et al., 2008). Incorporation of RGDS, the adhesive ligand found in fibronectin, similarly induced cell dissemination in poly(ethylene) glycol hydrogels (Beck et al., 2013). Further, glioma cells adhere more strongly in HA matrices that contain RGDS, potentially due to augmented integrinmediated mechanotransduction in HA (Chopra et al., 2014; Kim and Kumar, 2014).

\section{Topographical Cues}

Topographical cues present within the tissue can also enhance migration. While the brain is relatively non-fibrous and amorphous, basement membrane-rich blood vessels are a prime substrate on which glioma cells migrate within perivascular spaces (Cuddapah et al., 2014). Herrera-Perez et al. (2015) showed that pseudovessels of Matrigel-coated collagen-oligomer fibrils increased the speed of glioma cell migration across a $3 \mathrm{D}$ collagen-HA matrix. White matter tracts in the brain are also a frequent route of migration. Using core-shell electrospun nanofibers to mimic white matter tracts, Rao et al. (2013) found that glioma cell morphology, migration speed, and focal adhesion kinase expression were all sensitive to fiber mechanics and composition. Altering the design parameters of fibrous biomaterials can therefore offer precise control over glioma migration.

\section{Mechanical Forces}

A major driving force for using biomaterials in cell culture platforms is the ability to control biomechanical forces, often independently from the chemical composition. The mechanical properties of a scaffold influence a wide range of cellular behaviors, including proliferation, migration, and stem cell fate (Engler et al., 2006; Ulrich et al., 2009; Seidlits et al., 2010). It is well described that many tumors outside the brain are stiffer than the surrounding tissue. In glioma, tissue mechanics appear to be extremely heterogeneous, but the tumor is likely stiffer than normal brain, which has a Young's modulus around $1.4 \mathrm{kPa}$ (Miroshnikova et al., 2016). While the exact physiological properties are controversial, stiffer matrices promote glioma dissemination. Increasing the stiffness of PEG hydrogels decreased proliferation of U87 cells and increased the number of cell protrusions (Wang et al., 2014). Similar results were found using fibronectin-based matrices on which tumor cell spread and speed of migration increased with modulus while proliferation rate decreased compared to softer substrates (Ulrich et al., 2009). 
Fluid flow and shear stress are also felt by glioma cells in the tumor microenvironment (Munson and Shieh, 2014). These forces have been recreated in vitro using HA matrices (Polacheck et al., 2011; Qazi et al., 2011; Munson et al., 2013). Interstitial flow on the order of $0.1-1 \mu \mathrm{m} / \mathrm{s}$ generally increased glioma cell invasion, although patient-derived glioma stem cells showed variable responses (Kingsmore et al., 2016). Manipulation of the matrix to reduce glycocalyx assembly (Qazi et al., 2013) or CD44-binding (Kingsmore et al., 2016) attenuated these effects, indicating a link between flow and the surrounding 3D matrix.

\section{Implications for Therapeutic Translation}

Biomaterials often promote cell recruitment into an implantation site after neural injury (Ghuman et al., 2016; Nih et al., 2017). A similar approach may be beneficial for promoting glioma migration into an implanted material following resection. The properties of the implanted matrix should overcome the malignancy-enhancing properties of HA in the brain, either by disrupting binding or providing effective competition. Using a low molecular weight version of HA instead of high molecular weight may promote local anti-tumor inflammation and disrupt growth factor signaling (Fuchs et al., 2013; Rayahin et al., 2015). Incorporation of components such as fibronectin or RGDS could also preferentially promote stronger binding between invaded cells and the material vs. the parenchyma (Kim and Kumar, 2014). Fibrous materials would likely increase glioma invasion into the cavity. In fact, inducing migration through topography has already proved feasible and beneficial for GBM therapy (Jain et al., 2014). Additionally, the implanted matrix should be relatively stiffer than the brain to promote durotaxis, or migration up a stiffness gradient, of glioma cells and stem-like cells but deter migration of neural cells, which prefer softer substrates (Flanagan et al., 2002; Hadden et al., 2017). The caveat is that mechanical mismatch can promote potentially detrimental astrogliosis (Prodanov and Delbeke, 2016). Matrices that are initially stiffer and gradually soften over time may have a defined niche, in this case.

\section{CONTROLLING BIOCHEMICAL CUE PRESENTATION}

\section{Cytokine and Growth Factor Gradients}

Cytokines and growth factors originating from both glioma and parenchymal cells are associated with the progression of glioma and response to therapy, as previously reviewed (Iwami et al., 2011; Zhu et al., 2012). In vivo, natural heterogeneity is formed as tumor and parenchymal cells secrete biological molecules, which then differentially bind to the surrounding matrix and form gradients, sources, and sinks within the tissue. Recreating gradients in vitro using combinations of microfluidics, biomaterials, and various cells has been a focus of models for the study of both cancer (Keenan and Folch, 2008; Pedron et al., 2015) and regenerative medicine (Khang, 2015). Microfluidic devices and tissue culture insert models have both been used to show that in situ gradients of CXCL12 within 3D hydrogels directly promote glioma migration up the chemokine gradient (Munson et al., 2013; Addington et al., 2015; Kingsmore et al., 2016).

Cytokines are also implicated in the maintenance of glioma stem cells, a potential driver of glioma recurrence. Glial cells and recruited endothelial cells secrete factors such as bFGF that promote stem cell maintenance (Fessler et al., 2015). Blocking the effect of these cytokines offers potential to slow or halt proliferation of glioma cells. Affinity binding peptides have been incorporated into biomaterials for controlling release of bFGF, but these materials could inversely act as effective cytokine sinks (Lin and Anseth, 2009). A similar approach using an RNA aptamer to block PDGFR $\beta$ was shown effective at slowing glioma growth (Camorani et al., 2014). Designing materials to promote cell differentiation, as is common in regenerative medicine, may be equally applicable to treating glioma (Benoit et al., 2008).

\section{Oxygen}

Aberrant vasculature and unchecked tumor growth produce hypoxic or low oxygen-containing regions within the tumor and invading tumor clusters (called pseudopalisades; Rong et al., 2006). Hypoxia is implicated in increasing angiogenesis, stem cell maintenance, immunosuppression, and cancer cell therapeutic resistance (Colwell et al., 2017). Thus, incorporation of oxygen gradients within in vitro systems has been used to study a major effector of glioma outcomes. Use of $3 \mathrm{D}$ systems or spheroid culture naturally introduce regions of hypoxia based on thickness and permeability of the materials used. Recently, an in vitro PEGbased system showed that immobilization of the $\mathrm{O}_{2}$-consuming enzymes glucose oxidase and catalase effectively induced hypoxia and upregulated genes known to contribute to cancer metastasis (Dawes et al., 2017). The opposite would therefore be useful for glioma therapy: generating oxygen gradients and preventing hypoxia. Validating this approach, a paper-based PET mesh layering system showing that linear gradients of oxygen in culture functioned as a primary chemoattractant and increased invasion of lung adenocarcinoma cells (Mosadegh et al., 2015). Oxygen-creating biomaterials have been tested in regenerative medicine, showing sustain oxygen release for weeks and reducing hypoxia until angiogenesis can occur (Pedraza et al., 2012).

\section{Implications for Therapeutic Translation}

The ability to control spatiotemporal chemical gradients within the post-resection cavity has far-reaching implications for glioma therapy. An ideal biomaterial would trigger glioma cell egress from the brain parenchyma into the material through establishing chemical gradients of chemotactic factors such as oxygen or CXCL12. Alternatively, the material could eliminate or disrupt pro-malignant cytokine signaling through either release of receptor blockers or sequestration of factors that aid glioma stem cell proliferation and maintenance. Dual-release or multifunctional biomaterials would likely be optimal. Materials that enable temporally-regulated release and/or capture dynamics, similar to those used in regenerative medicine (Spiller et al., 2015), are particularly promising since they may simultaneously promote parenchyma egress, glioma stem cell differentiation, and loss of acquired drug resistance. 


\section{REMODELING THE CELLULAR MICROENVIRONMENT}

\section{Angiogenesis}

One hallmark of cancer is the ability to induce aberrant angiogenesis (Hanahan and Weinberg, 2011). Multiple models of angiogenesis have been engineered and used in vitro (Kimlin et al., 2013), although few have been described for co-culture of glioma cells and endothelial cells (Nguyen et al., 2016). Glioma cells secrete high levels of pro-angiogenic vascular endothelial growth factor (VEGF)-A which promotes blood vessel sprouting (Folkins et al., 2009). The ECM can act to sequester or locally retain VEGF-A, thereby amplifying resultant uncontrolled angiogenesis (Belair et al., 2016). Additionally, glioma cells in vivo physically displace astrocytic endfeet from the surface of blood vessels, disrupting the blood-brain barrier (BBB) and astrocytic control of vascular tone (Cuddapah et al., 2014; Watkins et al., 2014). While anti-angiogenesis strategies were initially promising for limiting glioma progression, the VEGFspecific antibody bevacizumab (Avastin) completely ablated tumor blood vessels and actually enhanced tumor growth by upregulating hypoxia-inducible pathways (Conley et al., 2012). A more apt approach may be to control availability of proangiogenic factors to promote vascular normalization.

\section{Immune Cell Modulation}

Another hallmark of cancer is the promotion of pro-tumor inflammation (Hanahan and Weinberg, 2011). Monocytederived cells can account for nearly $60 \%$ of the tumor bulk (Yuan et al., 2014). Initial studies proposed that gliomaassociated macrophages were conditioned toward alternative, M2 activation, but recent evidence suggests this characterization requires refinement (Mantovani et al., 2002; Szulzewsky et al., 2015; Gabrusiewicz et al., 2016). Early in tumor development, anti-inflammatory cytokines enable tumor cells to evade the host immune response (Zitvogel et al., 2006; Razavi et al., 2016). Later, immunotolerance can occur due to secretion of tolerogenic cytokines and ligands such as TGF $\beta$, IL-10, and PDL1 (Razavi et al., 2016). Glioma-derived ECM molecules also alter immune cell phenotype, with periostin acting to recruit and train monocytes toward pro-tumor phenotypes and tenascin-c protecting tumor cells from immune surveillance by arresting T-cell activation (Jachetti et al., 2015; Zhou et al., 2015).

While early biomaterials aimed to reduce the immune response (Bryers et al., 2012), more recent advances have resulted in development of immunomodulatory biomaterials (Hubbell et al., 2009) and immunotherapeutic biomaterials (Swartz et al., 2012). Biomaterial-based regulation of macrophage polarization was recently reviewed elsewhere (Sridharan et al., 2015). Although regenerative approaches typically focus on promoting anti-inflammatory immune cell phenotypes, the opposite is also conceivable. These approaches could easily be tailored toward anti-cancer immunotherapy, as well. $\mathrm{T}$ cell modulation is a rapidly growing and promising field, with several strategies currently being tested: checkpoint inhibitor targeting of programmed cell death protein (PD)-1, chimeric antigen receptor (CAR) $\mathrm{T}$ cell therapy, and dendritic cell therapy (Tumeh et al., 2014; Garg et al., 2017; O’Rourke et al., 2017).

\section{Glial Cell Modulation}

The glioma tumor microenvironment uniquely contains a brain-specific class of cells known collectively as glia, in part comprising astrocytes and microglia. Astrocytes provide trophic and functional support for neurons, and microglia are the resident immune cells of the central nervous system. Gliomaassociated factors such as CCL21 and the proteoglycan versican promote a pro-tumor phenotype in microglia (Vinnakota et al., 2013; Hu et al., 2015). Glioma cells communicate with astrocytes via connexin-43 gap junctions to promotes glioma invasion, potentially through exchange of double stranded DNA, as was observed with metastatic breast cancer cells (Chen et al., 2016; Sin et al., 2016).

There is limited knowledge on the effects of combining glial cells in 3D culture with glioma cells. Recent histological evidence revealed that the balance between reactive astrocytes and microglia correlated with GBM patient prognosis; therefore, it will be important to investigate the combination of these cell types in the future (Yuan et al., 2016). It also remains unclear if tumor-associated astrocytes are functionally different than other reactive astrocytes, particularly after the mechanical stress of surgical resection. Nonetheless, material interventions for tissue regeneration often target astrocytic "glial scarring." A mixture of collagen, hyaluronic acid, and Matrigel maintained astrocytes in a quiescent state in vitro (Placone et al., 2015). Additionally, a laminin-inspired self-assembling peptide hydrogel attenuated glial scarring following a stab injury (Maclean et al., 2017).

\section{Implications for Therapeutic Translation}

Biomaterials are routinely used to target the cellular microenvironment to promote healing. A similar approach may prove useful for limiting glioma recurrence. Implanting a material with immobilized pro-angiogenic factors may help constructively direct angiogenesis within the resection cavity to promote $\mathrm{BBB}$ formation and oxygen normalization while restricting vessel development in the parenchyma ( $\mathrm{Li}$ et al., 2017). A matrix that irreversibly sequesters VEGF-A from the surrounding tumor microenvironment may have similar effects. The adaptive immune system can be redirected using biomaterial-based vaccines to elicit potent, antigen-specific $\mathrm{T}$ cell responses, including in glioma (Ali et al., 2011; Purwada et al., 2014; Cheung et al., 2018). Reversing pro-tumor polarization in innate immune cells and glia will likely require a nuanced balance between pro- and anti-inflammatory phenotypes. In this case, it would be useful to temporally control release and/or presentation of different factors (Spiller et al., 2015). Enzyme-releasing materials could assist in mitigating the effects of glioma-derived ECM molecules (Qu et al., 2013). Additionally, astrocytes may be specifically targeted using therapeutic connectosomes to override cell-cell communication with glioma (Gadok et al., 2016). The foremost objective must remain eliminating the cancer cells, therefore fibrous materials may again be preferred given it proves desirable to promote pro-healing phenotypes in the long run (Sridharan et al., 2015). 


\section{CONCLUSIONS}

Although we use the in vivo environment to educate development of defined in vitro models, we rarely do the inverse in cancer. The complexity of glioblastoma has thus far proven difficult to capture in vitro, and unfortunately no current model can accurately predict the translational success of a therapy. Here, we proposed synthesizing the collective knowledge from in vitro models to inform tissue-level interventions through rational design of therapeutic biomaterials. Several strategies may be particularly relevant: Controlling angiogenesis by presentation of VEGF-A and FGF to enable better drug delivery to tumor remnants; induction of immunogenic response through growth factor and chemokine presentation to induce immune infiltration and anti-tumor differentiation; or increased stiffness coupled with topography and/or chemokines such as CXCL12 to encourage tumor cell migration away from healthy tissue.

\section{REFERENCES}

Addington, C. P., Heffernan, J. M., Millar-Haskell, C. S., Tucker, E. W., Sirianni, R. W., and Stabenfeldt, S. E. (2015). Enhancing neural stem cell response to SDF- $1 \alpha$ gradients through hyaluronic acid-laminin hydrogels. Biomaterials 72 , 11-19. doi: 10.1016/j.biomaterials.2015.08.041

Ali, O. A., Doherty, E., Bell, W. J., Fradet, T., Hudak, J., Laliberte, M. T., et al. (2011). Biomaterial-based vaccine induces regression of established intracranial glioma in rats. Pharm. Res. 28, 1074-1080. doi: 10.1007/s11095-010-0361-x

Bagó, J. R., Pegna, G. J., Okolie, O., and Hingtgen, S. D. (2016). Fibrin matrices enhance the transplant and efficacy of cytotoxic stem cell therapy for postsurgical cancer. Biomaterials 84, 42-53. doi: 10.1016/j.biomaterials.2016.01.007

Bastiancich, C., Bianco, J., Vanvarenberg, K., Ucakar, B., Joudiou, N., Gallez, B., et al. (2017). Injectable nanomedicine hydrogel for local chemotherapy of glioblastoma after surgical resection. J. Control. Release 264, 45-54. doi: 10.1016/j.jconrel.2017.08.019

Beck, J. N., Singh, A., Rothenberg, A. R., Elisseeff, J. H., and Ewald, A. J. (2013). The independent roles of mechanical, structural and adhesion characteristics of 3D hydrogels on the regulation of cancer invasion and dissemination. Biomaterials 34, 9486-9495. doi: 10.1016/j.biomaterials.2013.08.077

Belair, D. G., Miller, M. J., Wang, S., Darjatmoko, S. R., Binder, B. Y. K., Sheibani, N., et al. (2016). Differential regulation of angiogenesis using degradable VEGF-binding microspheres. Biomaterials 93, 27-37. doi: 10.1016/j.biomaterials.2016.03.021

Ben-David, U., Ha, G., Tseng, Y. Y., Greenwald, N. F., Oh, C., Shih, J., McFarland, J. M., et al. (2017). Patient-derived xenografts undergo mouse-specific tumor evolution. Nat. Genet. 49, 1567-1575. doi: 10.1038/ng.3967

Benoit, D. S., Schwartz, M. P., Durney, A. R., and Anseth, K. S. (2008), Small functional groups for controlled differentiation of hydrogel-encapsulated human mesenchymal stem cells. Nat. Mater. 7, 816-823. doi: 10.1038/nmat2269

Bryers, J. D., Giachelli, C. M., and Ratner, B. D. (2012). Engineering biomaterials to integrate and heal: the biocompatibility paradigm shifts. Biotechnol. Bioeng. 109, 1898-1911. doi: 10.1002/bit.24559

Camorani, S., Esposito, C. L., Rienzo, A., Catuogno, S., Iaboni, M., Condorelli, G., et al. (2014). Inhibition of receptor signaling and of glioblastomaderived tumor growth by a novel PDGFR $\beta$ aptamer. Mol. Ther. 22, 828-841. doi: $10.1038 / \mathrm{mt} .2013 .300$

Cha, J., Kang, S. G., and Kim, P. (2016). Strategies of mesenchymal invasion of patient-derived brain tumors: microenvironmental adaptation. Sci. Rep. 6:24912. doi: 10.1038/srep24912

Cha, J., and Kim, P. (2017). Biomimetic strategies for the glioblastoma microenvironment. Front. Mater. 4:45. doi: 10.3389/fmats.2017.00045

Chen, Q., Boire, A., Jin, X., Valiente, M., Emrah Er, E., Lopez-Soto, A., et al. (2016). Carcinoma-astrocyte gap junctions promote brain metastasis by cGAMP transfer. Nature 533, 493-498. doi: 10.1038/nature18268
Regardless, using biomaterials as a tissue engineering approach to treat glioblastoma is an unexplored possibility. Because a plethora of in vitro models have used a host of different biomaterials and approaches, there may already be a strategy hidden within these studies that could assist in the fight against this deadly disease.

\section{AUTHOR CONTRIBUTIONS}

All authors developed the presented conceptual ideas, conducted literature review, drafted the manuscript, and approved it for publication.

\section{FUNDING}

The authors would like to acknowledge support by the National Institutes of Health (1R01CA222563-01).
Cheung, A. S., Zhang, D. K. Y., Koshy, S. T., and Mooney, D. J. (2018). Scaffolds that mimic antigen-presenting cells enable ex vivo expansion of primary $\mathrm{T}$ cells. Nat. Biotechnol. 36, 160-169. doi: 10.1038/nbt.4047

Chopra, A., Murray, M. E., Byfield, F. J., Mendez, M. G., Halleluyan, R., Restle, D. J., et al. (2014). Augmentation of integrin-mediated mechanotransduction by hyaluronic acid. Biomaterials 35, 71-82. doi: 10.1016/j.biomaterials.2013.09.066

Colwell, N., Larion, M., Giles, A. J., Seldomridge, A. N., Sizdahkhani, S., Gilbert, M. R., et al. (2017). Hypoxia in the glioblastoma microenviornment: shaping the phenotype of cancer stem-like cells. Neurooncology 19, 887-896. doi: 10.1093/neuonc/now258

Conley, S. J., Gheordunescu, E., Kakarala, P., Newman, B., Korkaya, H., Heath, A. N., et al. (2012). Antiangiogenic agents increase breast cancer stem cells via the generation of tumor hypoxia. Proc. Natl. Acad. Sci. U.S.A. 109, 2784-2789. doi: 10.1073/pnas.1018866109

Cuddapah, V. A., Robel, S., Watkins, S., and Sontheimer, H. (2014). A neurocentric perspective on glioma invasion. Nat. Rev. Neurosci. 15, 455-465. doi: $10.1038 / \mathrm{nrn} 3765$

Dawes, C. S., Konig, H., and Lin, C. C. (2017). Enzyme-immobilized hydrogels to create hypoxia for in vitro cancer cell culture. J. Biotechnol. 248, 25-34. doi: 10.1016/j.jbiotec.2017.03.007

Eke, I., and Cordes, N. (2011). Radiobiology goes 3D: how ECM and cell morphology impact on cell survival after irradiation. Radiother. Oncol. 99, 271-278. doi: 10.1016/j.radonc.2011.06.007

Engler, A. J., Sen, S., Sweeney, H. L., and Discher, D. E. (2006). Matrix elasticity directs stem cell lineage specification. Cell 126, 677-689. doi: 10.1016/j.cell.2006.06.044

Fessler, E., Borovski, T., and Medema, J. P. (2015). Endothelial cells induce cancer stem cell features in differentiated glioblastoma cells via bFGF. Mol. Cancer 14:157. doi: 10.1186/s12943-015-0420-3

Flanagan, L. A., Ju, Y. E., Marg, B., Osterfield, M., and Janmey, P. A. (2002). Neurite branching on deformable substrates. Neuroreport 13, 2411-2415. doi: 10.1097/00001756-200212200-00007

Florczyk, S. J., Wang, K., Jana, S., Wood, D. L., Sytsma, S. K., Sham, J., et al. (2013). Porous chitosan-hyaluronic acid scaffolds as a mimic of glioblastoma microenvironment ECM. Biomaterials 34, 10143-10150. doi: 10.1016/J.BIOMATERIALS.2013.09.034

Folkins, C., Shaked, Y., Man, S., Tang, T., Lee, C. R., Zhu, Z., et al. (2009). Glioma tumor stem-like cells promote tumor angiogenesis and vasculogenesis via vascular endothelial growth factor and stromal-derived factor 1. Cancer Res. 69, 7243-7251. doi: 10.1158/0008-5472.CAN-09-0167

Fuchs, K., Hippe, A., Schmaus, A., Homey, B., Sleeman, J. P., and Orian-Rousseau, V. (2013). Opposing effects of high- and low-molecular weight hyaluronan on CXCL12-Induced CXCR4 signaling depend on CD44. Cell Death Dis. 4, e819-e819. doi: 10.1038/cddis.2013.364 
Gabrusiewicz, K., Rodriguez, B., Wei, J., Hashimoto, Y., Healy, L. M., Maiti, S. N., et al. (2016). Glioblastoma-infiltrated innate immune cells resemble M0 macrophage phenotype. JCI Insight 1:e85841. doi: 10.1172/jci.insight.85841

Gadok, A. K., Busch, D. J., Ferrati, S., Li, B., Smyth, H. D., and Stachowiak, J. C. (2016). Connectosomes for direct molecular delivery to the cellular cytoplasm. J. Am. Chem. Soc. 138, 12833-12840. doi: 10.1021/jacs.6b05191

Garg, A. D., Coulie, P. G., Van den Eynde, B. J., and Agostinis, P. (2017). Integrating next-generation dendritic cell vaccines into the current cancer immunotherapy landscape. Trends Immunol. 38, 577-593. doi: 10.1016/j.it.2017.05.006

Ghuman, H., Massensini, A. R., Donnelly, J., Kim, S. M., Medberry, C. J., Badylak, S. F., et al. (2016). ECM hydrogel for the treatment of stroke: characterization of the host cell infiltrate. Biomaterials 91, 166-181. doi: 10.1016/j.biomaterials.2016.03.014

Gritsenko, P., Leenders, W., and Friedl, P. (2017). Recapitulating in vivo-like plasticity of glioma cell invasion along blood vessels and in astrocyte-rich stroma. Histochem. Cell Biol. 148, 395-406. doi: 10.1007/s00418-017-1604-2

$\mathrm{Gu}$, L., and Mooney, D. J. (2015). Biomaterials and emerging anticancer therapeutics: engineering the microenvironment. Nat. Rev. Cancer 16, 56-66. doi: $10.1038 /$ nrc. 2015.3

Hadden, W. J., Young, J. L., Holle, A. W., McFetridge, M. L., Kim, D. Y., Wijesinghe, P., et al. (2017). Stem cell migration and mechanotransduction on linear stiffness gradient hydrogels. Proc. Natl. Acad. Sci. U.S.A. 114, 5647-5652. doi: $10.1073 /$ pnas. 1618239114

Hanahan, D., and Weinberg, R. A. (2011). Hallmarks of cancer: the next generation. Cell 144, 646-674. doi: 10.1016/j.cell.2011.02.013

Heffernan, J. M., Overstreet, D. J., Le, L. D., Vernon, B. L., and Sirianni, R. W. (2015). Bioengineered scaffolds for 3D analysis of glioblastoma proliferation and invasion. Ann. Biomed. Eng. 43, 1965-1977. doi: 10.1007/s10439-014-1223-1

Heffernan, J. M., and Sirianni, R. W. (2018). Modeling microenvironmental regulation of glioblastoma stem cells: a biomaterials perspective. Front. Mater. 5:7. doi: $10.3389 /$ fmats. 2018.00007

Herrera-Perez, M., Voytik-Harbin, S. L., and Rickus, J. L. (2015). "Extracellular matrix properties regulate the migratory response of glioblastoma stem cells in three-dimensional culture," in Tissue Engineering Part A 21 (19-20) (New Rochelle, NY: Mary Ann Liebert, Inc.), 2572-2582.

Hu, F., a Dzaye, O. D., Hahn, A., Yu, Y., Scavetta, R. J., Dittmar, G., et al. (2015). Glioma-derived versican promotes tumor expansion via gliomaassociated microglial/macrophages Toll-like receptor 2 signaling. Neuro Oncol. 17, 200-210. doi: 10.1093/neuonc/nou324

Hu, B., Kong, L. L., Matthews, R. T., and Viapiano, M. S. (2008). The Proteoglycan brevican binds to fibronectin after proteolytic cleavage and promotes glioma cell motility. J. Biol. Chem. 283, 24848-24859. doi: 10.1074/jbc.M801433200

Hubbell, J. A., Thomas, S. N., and Swartz, M. A. (2009). Materials engineering for immunomodulation. Nature 462, 449-460. doi: 10.1038/nature08604

Iwami, K., Natsume, A., and Wakabayashi, T. (2011). Cytokine networks in glioma. Neurosurg. Rev. 34, 253-264. doi: 10.1007/s10143-011-0320-y

Jachetti, E., Caputo, S., Mazzoleni, S., Brambillasca, C. S., Parigi, S. M., Grioni, M., et al. (2015). Tenascin-C protects cancer stem-like cells from immune surveillance by arresting T-cell activation. Cancer Res. 75, 2095-2108. doi: 10.1158/0008-5472.CAN-14-2346

Jain, A., Betancur, M., Patel, G. D., Valmikinathan, C. M., Mukhatyar, V. J., Vakharia, A., et al. (2014). Guiding intracortical brain tumour cells to an extracortical cytotoxic hydrogel using aligned polymeric nanofibres. Nat. Mater. 13, 308-316. doi: 10.1038/nmat3878

Keenan, T. M., and Folch, A. (2008). Biomolecular gradients in cell culture systems. Lab. Chip 8, 34-57. doi: 10.1039/b711887b

Khang, G. (2015). Evolution of gradient concept for the application of regenerative medicine. Biosurface Biotribol. 1, 202-213. doi: 10.1016/j.bsbt.2015.08.004

Kim, Y., and Kumar, S. (2014). CD44-mediated adhesion to hyaluronic acid contributes to mechanosensing and invasive motility. Mol. Cancer Res. 12, 1416-1429. doi: 10.1158/1541-7786.MCR-13-0629

Kimlin, L. C., Casagrande, G., and Virador, V. M. (2013). In vitro threedimensional (3D) models in cancer research: an update. Mol. Carcinog. 52, 167-182. doi: 10.1002/mc.21844

Kingsmore, K. M., Logsdon, D. K., Floyd, D. H., Peirce, S. M., Purow, B. W., and Munson, J. M. (2016). Interstitial flow differentially increases patient-derived glioblastoma stem cell invasion via CXCR4, CXCL12, and CD44-mediated mechanisms. Integr. Biol. 8, 1246-1260. doi: 10.1039/C6IB00167J

Li, S., Nih, L. R., Bachman, H., Fei, P., Li, Y., Nam, E., et al. (2017). Hydrogels with precisely controlled integrin activation dictate vascular patterning and permeability. Nat. Mater. 16, 953-961. doi: 10.1038/nmat4954

Lin, C. C., and Anseth, K. S. (2009). Controlling affinity binding with peptide-functionalized poly(ethylene Glycol) hydrogels. Adv. Funct. Mater. 19, 2325-2331. doi: 10.1002/adfm.200900107

Logun, M. T., Bisel, N. S., Tanasse, E. A., Zhao, W., Gunasekera, B., Mao, L., et al. (2016). Glioma cell invasion is significantly enhanced in composite hydrogel matrices composed of chondroitin 4- and 4,6-sulfated glycosaminoglycans. J. Mater. Chem. B 4, 6052-6064. doi: 10.1039/C6TB01083K

Maclean, F. L., Lau, C. L., Ozergun, S., O’Shea, R. D., Cederfur, C., Wang, J., et al. (2017). Galactose-functionalised PCL nanofibre scaffolds to attenuate inflammatory action of astrocytes in vitro and in vivo. J. Mater. Chem. B 5, 4073-4083. doi: 10.1039/C7TB00651A

Mantovani, A., Sozzani, S., Locati, M., Allavena, P., and Sica, A. (2002). Macrophage polarization: tumor-associated macrophages as a paradigm for polarized M2 mononuclear phagocytes. Trends Immunol. 23, 549-555. doi: 10.1016/S1471-4906(02)02302-5

Miroshnikova, Y. A., Mouw, J. K., Barnes, J. M., Pickup, M. W., Lakins, J. N., Kim, Y., et al. (2016). Tissue mechanics promote IDH1-Dependent HIF1 $\alpha$-tenascin C feedback to regulate glioblastoma aggression. Nat. Cell Biol. 18, 1336-1345. doi: $10.1038 /$ ncb3429

Mosadegh, B., Lockett, M. R., Thu, K., Simon, K. A., Gilbert, K., Hillier, S., et al. (2015). Biomaterials a paper-based invasion assay : assessing chemotaxis of cancer cells in gradients of oxygen 52, 262-271. doi: 10.1016/j.biomaterials.2015.02.012

Munson, J. M., Bellamkonda, R. V., and Swartz, M. A. (2013). Interstitial flow in a $3 \mathrm{~d}$ microenvironment increases glioma invasion by a cxcr4-dependent mechanism. Cancer Res. 73, 1536-1546. doi: 10.1158/0008-5472.CAN-12-2838

Munson, J. M., and Shieh, A. C. (2014). Interstitial fluid flow in cancer: implications for disease progression and treatment. Cancer Manag. Res. 6 , 317-328. doi: 10.2147/CMAR.S65444

Nguyen, D. T., Fan, Y., Akay, Y. M., and Akay, M. (2016). Investigating glioblastoma angiogenesis using a 3D in vitro GelMA microwell platform. IEEE Trans. Nanobiosci. 15, 289-293. doi: 10.1109/TNB.2016.2528170

Nih, L. R., Sideris, E., Carmichael, S. T., and Segura, T. (2017). Injection of Microporous Annealing Particle (MAP) hydrogels in the stroke cavity reduces gliosis and inflammation and promotes NPC migration to the lesion. Adv. Mater. 29:1606471. doi: 10.1002/adma.201606471

O’Rourke, D. M., Nasrallah, M. P., Desai, A., Melenhorst, J. J., Mansfield, K., Morrissette, J. J. D., Martinez-Lage, M., et al. (2017). A single dose of peripherally infused EGFRvIII-directed CAR T cells mediates antigen loss and induces adaptive resistance in patients with recurrent glioblastoma. Sci. Transl. Med. 9:eaaa0984. doi: 10.1126/scitranslmed.aaa0984

Pedraza, E., Coronel, M. M., Fraker, C. A., Ricordi, C., and Stabler, C. L. (2012) Preventing hypoxia-induced cell death in beta cells and islets via hydrolytically activated, oxygen-generating biomaterials Proc. Natl. Acad. Sci. U.S.A. 109, 4245-4250. doi: 10.1073/pnas.1113560109

Pedron, S., Becka, E., and Harley, B. A. (2013). Regulation of glioma cell phenotype in 3D matrices by hyaluronic acid. Biomaterials 34, 7408-7417. doi: 10.1016/J.BIOMATERIALS.2013.06.024

Pedron, S., Becka, E., and Harley, B. A. (2015). Spatially gradated hydrogel platform as a $3 \mathrm{D}$ engineered tumor microenvironment. Adv. Mater. 27, 1567-1572. doi: 10.1002/adma.201404896

Placone, A. L., McGuiggan, P. M., Bergles, D. E., Guerrero-Cazares, H., Quiñones-Hinojosa, A., and Searson, P. C. (2015). Human astrocytes develop physiological morphology and remain quiescent in a novel $3 \mathrm{D}$ matrix. Biomaterials 42, 134-143. doi: 10.1016/j.biomaterials.2014.11.046

Polacheck, W. J., Charest, J. L., and Kamm, R. D. (2011). Interstitial flow influences direction of tumor cell migration through competing mechanisms. Proc. Natl. Acad. Sci. U.S.A. 108, 11115-11120. doi: 10.1073/pnas.1103 581108

Pradhan, S., Hassani, I., Clary, J. M., and Lipke, E. A. (2016). Polymeric biomaterials for in vitro cancer tissue engineering and drug testing applications. Tissue Eng. B Rev. 22, 470-484. doi: 10.1089/ten.teb.2015.0567 
Prodanov, D., and Delbeke, J. (2016). Mechanical and biological interactions of implants with the brain and their impact on implant design. Front. Neurosci. 10:11. doi: 10.3389/fnins.2016.00011

Purwada, A., Roy, K., and Singh, A. (2014). Engineering vaccines and niches for immune modulation. Acta Biomater. 10, 1728-1740. doi: 10.1016/j.actbio.2013.12.036

Qazi, H., Palomino, R., Shi, Z.-D., Munn, L. L., and Tarbell, J. M. (2013). Cancer cell glycocalyx mediates mechanotransduction and flow-regulated invasion. Integr. Biol. 5, 1334-1343. doi: 10.1039/c3ib40057c

Qazi, H., Shi, Z. D., and Tarbell, J. M. (2011). Fluid shear stress regulates the invasive potential of glioma cells via modulation of migratory activity and matrix metalloproteinase expression. PLOS ONE 6:e20348. doi: 10.1371/journal.pone.0020348

Qu, F., Lin, J. M., Esterhai, J. L., Fisher, M. B., and Mauck, R. L. (2013). Biomaterialmediated delivery of degradative enzymes to improve meniscus integration and repair. Acta Biomater. 9, 6393-6402. doi: 10.1016/j.actbio.2013.01.016

Rao, S. S., Nelson, M. T., Xue, R., DeJesus, J. K., Viapiano, M. S., Lannutti, J. J., et al. (2013). Mimicking white matter tract topography using core-shell electrospun nanofibers to examine migration of malignant brain tumors. Biomaterials 34 , 5181-5190. doi: 10.1016/j.biomaterials.2013.03.069

Rayahin, J. E., Buhrman, J. S., Zhang, Y., Koh, T. J., and Gemeinhart, R. A. (2015). High and low molecular weight hyaluronic acid differentially influence macrophage activation. ACS Biomater. Sci. Eng. 1, 481-93. doi: 10.1021/acsbiomaterials.5b00181

Razavi, S. M., Lee, K. E., Jin, B. E., Aujla, P. S., Gholamin, S., and Li, G. (2016). Immune evasion strategies of glioblastoma. Front. Surg. 3:11. doi: 10.3389/fsurg.2016.00011

Rong, Y., Durden, D. L., Van Meir, E. G., and Brat, D. J. (2006). 'Pseudopalisading' necrosis in glioblastoma: a familiar morphologic feature that links vascular pathology, hypoxia, and angiogenesis. J. Neuropathol. Exp. Neurol. 65, 529-539. doi: 10.1097/00005072-200606000-00001

Seidlits, S. K., Khaing, Z. Z., Petersen, R. R., Nickels, J. D., Vanscoy, J. E., Shear, J. B., et al. (2010). The effects of hyaluronic acid hydrogels with tunable mechanical properties on neural progenitor cell differentiation. Biomaterials 31, 3930-3940. doi: 10.1016/j.biomaterials.2010.01.125

Silver, D. J., Siebzehnrubl, F. A., Schildts, M. J., Yachnis, A. T., Smith, G. M., Smith, A. A., et al. (2013). Chondroitin sulfate proteoglycans potently inhibit invasion and serve as a central organizer of the brain tumor microenvironment. J. Neurosci. 33, 15603-15617. doi: 10.1523/JNEUROSCI.3004-12.2013

Silver, D. J., and Silver, J. (2014). Contributions of chondroitin sulfate proteoglycans to neurodevelopment, injury, and cancer. Curr. Opin. Neurobiol. 27, 171-178. doi: 10.1016/J.CONB.2014.03.016

Sin, W. C., Aftab, Q., Bechberger, J. F., Leung, J. H., Chen, H., and Naus, C. C. (2016). Astrocytes promote glioma invasion via the gap junction protein connexin43. Oncogene 35, 1504-1516. doi: 10.1038/onc.2015.210

Spiller, K. L., Nassiri, S., Witherel, C. E., Anfang, R. R., Ng, J., Nakazawa, K. R., et al. (2015). sequential delivery of immunomodulatory cytokines to facilitate the M1-to-M2 transition of macrophages and enhance vascularization of bone scaffolds. Biomaterials 37, 194-207. doi: 10.1016/j.biomaterials.2014.10.017

Sridharan, R., Cameron, A. R., Kelly, D. J., Kearney, C. J., and O’Brien, F. J. (2015). Biomaterial based modulation of macrophage polarization: a review and suggested design principles. Mater. Today. 18, 313-325. doi: 10.1016/j.mattod.2015.01.019

Swartz, M. A., Hirosue, S., and Hubbell, J. A. (2012). Engineering approaches to immunotherapy. Sci. Transl. Med. 4:148rv9. doi: 10.1126/scitranslmed. 3003763

Szulzewsky, F., Pelz, A., Feng, X., Synowitz, M., Markovic, D., Langmann, T., et al. (2015). Glioma-associated microglia/macrophages display an expression profile different from $\mathrm{m} 1$ and $\mathrm{m} 2$ polarization and highly express gpnmb and spp1. PLOS ONE 10:e0116644. doi: 10.1371/journal.pone.0116644
Tilghman, J., Wu, H., Sang, Y., Shi, X., Guerrero-Cazares, H., QuinonesHinojosa, A., et al. (2014). HMMR maintains the stemness and tumorigenicity of glioblastoma stem-like cells. Cancer Res. 74, 3168-3179. doi: 10.1158/0008-5472.CAN-13-2103

Tumeh, P. C., Harview, C. L., Yearley, J. H., Peter Shintaku, I., Taylor, E. J. M., Robert, L., et al. (2014). PD-1 blockade induces responses by inhibiting adaptive immune resistance. Nature 515, 568-571. doi: 10.1038/nature13954

Ulrich, T. A.,de Juan Pardo, E. M., and Kumar, S. (2009). The mechanical rigidity of the extracellular matrix regulates the structure, motility, and proliferation of glioma cells. Cancer Res. 69, 4167-4174. doi: 10.1158/0008-5472.CAN-08-4859

Vinnakota, K., Hu, F., Ku, M. C., Georgieva, P. B., Szulzewsky, F., Pohlmann, A., et al. (2013). Toll-like receptor 2 mediates microglia/brain macrophage MT1-MMP expression and glioma expansion. Neurooncology 15, 1457-1468. doi: 10.1093/neuonc/not115

Wait, S. D., Prabhu, R. S., Burri, S. H., Atkins, T. G., and Asher, A. L. (2015). Polymeric drug delivery for the treatment of glioblastoma. Neuro Oncol. 17 (Suppl. 2), ii9-ii23. doi: 10.1093/neuonc/nou360

Wang, C., Tong, X., and Yang, F. (2014). Bioengineered 3D brain tumor model to elucidate the effects of matrix stiffness on glioblastoma cell behavior using pegbased hydrogels. Mol. Pharmaceut. 11, 2115-2125. doi: 10.1021/mp5000828

Watkins, S., Robel, S., Kimbrough, I. F., Robert, S. M., Ellis-Davies, G., and Sontheimer, H. (2014). Disruption of astrocyte-vascular coupling and the blood-brain barrier by invading glioma cells. Nature Commun 5:4196. doi: $10.1038 /$ ncomms5196

Xia, S., Lal, B., Tung, B., Wang, S., Goodwin, C. R., and Laterra, J. (2016). Tumor microenvironment tenascin-C promotes glioblastoma invasion and negatively regulates tumor proliferation. Neuro Oncol. 18, 507-517. doi: 10.1093/neuonc/nov171

Xiao, W., Sohrabi, A., Seidlits, S., and Seidlits. (2017). Integrating the glioblastoma microenvironment into engineered experimental models. Future Science. 3, FSO18. doi: 10.4155/fsoa-2016-0094

Yuan, J. X., Bafakih, F. F., Mandell, J. W., Horton, B. J., and Munson, J. M. (2016). Quantitative analysis of the cellular microenvironment of glioblastoma to develop predictive statistical models of overall survival. J. Neuropathol. Exp. Neurol. 75, 1110-1123. doi: 10.1093/jnen/nlw090

Yuan, Z., Mehta, H. J., Mohammed, K., Nasreen, N., Roman, R., Brantly, M., et al. (2014). TREM-1 Is induced in tumor associated macrophages by Cyclooxygenase pathway in human non-small cell lung cancer. PLOS ONE 9:e94241. doi: 10.1371/journal.pone.0094241

Zhou, W., Ke, S. Q., Huang, Z., Flavahan, W., Fang, X., Paul, J., et al. (2015). Periostin secreted by glioblastoma stem cells recruits M2 tumour-associated macrophages and promotes malignant growth. Nat. Cell Biol. 17, 170-182. doi: $10.1038 /$ ncb3090

Zhu, V. F., Yang, J., Lebrun, D. G., and Li, M. (2012). Understanding the role of cytokines in glioblastoma multiforme pathogenesis. Cancer Lett. 316, 139-150. doi: 10.1016/j.canlet.2011.11.001

Zitvogel, L., Tesniere, A., and Kroemer, G. (2006). Cancer despite Immunosurveillance: immunoselection and Immunosubversion. Nat. Rev. Immunol. 6, 715-727. doi: 10.1038/nri1936

Conflict of Interest Statement: The authors declare that the research was conducted in the absence of any commercial or financial relationships that could be construed as a potential conflict of interest.

Copyright (C) 2018 Cornelison and Munson. This is an open-access article distributed under the terms of the Creative Commons Attribution License (CC BY). The use, distribution or reproduction in other forums is permitted, provided the original author(s) and the copyright owner are credited and that the original publication in this journal is cited, in accordance with accepted academic practice. No use, distribution or reproduction is permitted which does not comply with these terms. 